\title{
X-ray microanalysis of powders, obtained by electroerosion dispersion of the alloy W-Ni-Fe
}

\author{
R.A. Latypov ${ }^{1, *}$, E.V. Ageeva ${ }^{2}$, G.R. Latypova ${ }^{1}$ \\ ${ }^{1}$ Moscow Polytechnic University, street Bolshaya Semenovskaya street, 38, Moscow, Russia \\ ${ }^{2}$ South-West State University, street 50 years of October, 94, Kursk, Russia
}

\begin{abstract}
The results of X-ray microanalysis of powders, obtained by electroerosive dispersion of the W-Ni-Fe alloy with various electrical parameters of the device, are presented. Conducted researches, aimed at establishing the elemental composition of powders, obtained by electroerosion dispersion of the alloy W-Ni-Fe, will determine the most rational area of their practical application.
\end{abstract}

\section{Intorduction}

$\mathrm{W}-\mathrm{Ni}$-Fe alloys have a number of very valuable properties, thanks to which they are effectively used in many areas of technology [1-8].

The currently existing technologies for the production of $\mathrm{W}-\mathrm{Ni}-\mathrm{Fe}$ alloys are characterized by large tonnage, energy consumption, large production areas, low productivity, as well as environmental problems. One of the main problems with the use of these alloys today is the recycling of waste and its further use. Numerous attempts to bring tungsten out of these alloys, because of its high cost, have not been successfully completed, since none of the refractory compounds provides such high strength characteristics. Therefore, the problem of waste disposal of alloys of W-Ni-Fe is currently very relevant.

One of the most promising methods of utilization of virtually any electrically conductive material, including the alloy $\mathrm{W}-\mathrm{Ni}-\mathrm{Fe}$, characterized by relatively low energy consumption and ecological purity of the process, is the method of electroerosive dispersion (EED) [9-11].

The relevance of the work is determined by the important economic task of creating progressive, environmentally friendly, energy-saving and waste-free technologies for producing powders, including nano-sized, and their practical application.

For the development of technologies for the production of products from powders, obtained from waste $\mathrm{W}-\mathrm{Ni}-\mathrm{Fe}$, and assessing the effectiveness of their use, complex theoretical and experimental studies are needed. Conducting the planned activities will allow to solve the problem of waste disposal of $\mathrm{W}-\mathrm{Ni}-\mathrm{Fe}$ alloys and their further use and thereby reduce the cost of final products.

The method of EED is one of the promising methods for obtaining powders from virtually any conductive material, including ball bearing steel waste, and is distinguished by relatively low energy consumption and ecological cleanliness of the process [12-19].

\footnotetext{
*Corresponding author: latipov46@mail.ru
} 
Conducting the planned activities will solve the problem of waste disposal and their further use and thereby reduce the cost of the final product.

\section{Materials and methods}

For producing a powder from a solid alloy wastes by the electroerosion dispersing unit for EED of conductive materials, developed by the authors, and the ball-bearing steel wastes are used.

Wastes were loaded into a reactor filled with the working fluid - illuminating kerosene, the process was carried out at the following electrical parameters: voltage across the electrodes 140 ... 160V; capacity of discharge condensers $65 \mathrm{uF}$; pulse repetition frequency $160 \ldots 180 \mathrm{~Hz}$. As a result of local influence of short electric discharges between the electrodes destruction of material wastes occurred with formation of dispersed particles of the powder.

$\mathrm{X}$-ray microanalysis (XRM) was performed by energy-dispersive X-ray radiation analyzer EDAX, integrated in a scanning electron microscope Nova NanoSEM 450. By scanning electron microscopy using the secondary electron detector particles of powders sample were investigated.

By means energy dispersive X-ray radiation analyzer EDAX, integrated in scanning electron microscope Nova NanoSEM 450, spectra of the characteristic X-ray at different points on the surface of the powders sample were obtained.

Under X-ray microanalysis it should be understood the definition of the elemental composition of microscopic objects according to characteristic X-rays radiation instigated in them. For the analysis of the characteristic spectrum in the X-ray microanalysis (XRM) two types of spectrometers are used (without crystal or with analyzer-crystal), electronoptical system of a scanning electron microscope serves as a base for XRM.

In the interaction of the electron probe with a sample (Fig. 1 and Fig. 2), one of the excited signals is $\mathrm{X}$-ray radiation, which can be divided into: the characteristic and the braking.

The braking X-ray emission is caused by braking of the primary electrons in an electric (Coulomb) field of atoms in an analyzed material. The kinetic energy of the primary electrons in this case is partially or completely converted into the energy of X-rays. Accordingly, the radiation has a continuous spectrum with energy from zero to the incident electron energy and therefore it is also called the continuous X-rays. In X-ray microanalysis the braking radiation is undesirable, as a major contributor to the increasing background level and can' t be ruled out.

With the penetration of the primary electrons in the sample, they are slowed not only by the electric field of the atoms, but also a direct collision with the electrons of the atoms of the material. As a result, the primary electrons can knock electrons out from the inner K-, L-, or M-shells, leaving the atom of the sample in energetically excited state. The resultant vacancies are filled by electrons from higher energy levels. Atom goes to the ground state, the excess of energy is released in the form of X-ray quantum. Since the energy of arising quantum depends only on the energy of electron levels involved in the process, and they are specific to each element, there is a characteristic X-rays. So each atom has a very definite finite number of levels, between which transitions are possible only to a certain type, characteristic X-rays gives a discrete line spectrum. 


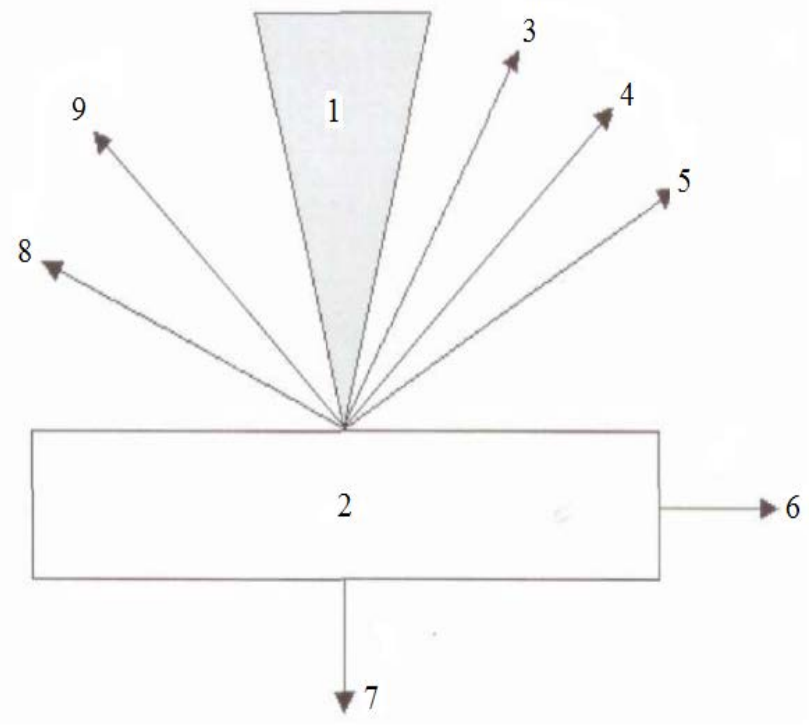

Fig. 1. Effects of the interaction of an electron ray with the object: 1 - electron ray, 2 - object, 3 reflected electrons, 4 - secondary electrons, 5 - Auger electrons, 6 - absorbed electrons current 7 passed electrons, 8 - cathodoluminescent radiation, 9 - X-ray radiation

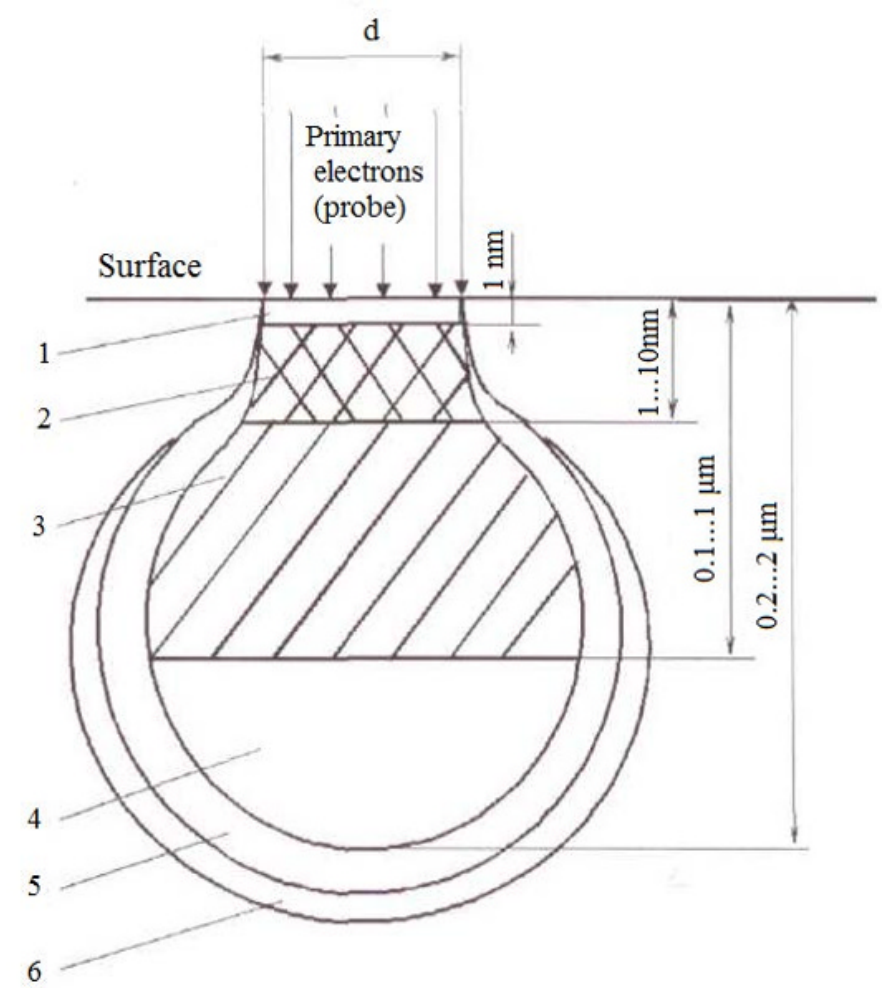

Fig. 2. Signal areas and space resolution under irradiation of the object surface with a flow of electrons (probe). Areas of generation of: 1 - auger electrons, 2 - secondary electrons, 3 - reflected electrons, 4 - characteristic X-ray radiation, 5 - deceleration X-ray radiation, 6 - fluorescence 
X-ray microanalysis is not possible to determine the light elements with atomic number less than 4 in the composition of the alloy. There are such difficulties with detection of elements, when L- or M- series lines of one element are superimposed on the K-series line of another element. An important characteristic of XRM is its locality, ie volume of the substance, in which the characteristic X-rays is excited. It is primarily determined by the diameter of the electron probe on the sample and depends on the accelerating voltage and the chemical composition of the material (Figure 2).

Analysis of the elements distribution can be made in a qualitative, semiquantitative and quantitative way. Qualitative analysis determines the type of elements, that are part of the test sample area. If a sample has several phases (sites), the chemical composition of which is unknown, a qualitative analysis is performed for each phase. Qualitative analysis is usually used to determine the nature of the elements distribution along the ground joint area. After a qualitative analysis, a quantitative analysis is often carried out in selected points, according to the received data the software allow to determine type of phase, based on its chemical composition.

Semi-quantitative analysis is realized, if it is required to define distribution of elements along the lines (linear analysis). Linear analysis is carried out by the method of step scanning, ie by sequential analysis at individual points. Thus, the quantitative determination of the elements concentration is performed with specified accuracy.

Waste of the alloy $\mathrm{W}-\mathrm{Ni}$-Fe was processed at the electro-erosion dispersion unit and distilled water was used as a working fluid. The powder was obtained with different installation modes, namely:

- Sample No. 1 was obtained with the following installation parameters: the voltage on the electrodes is $100 \mathrm{~V}$; capacity of discharge capacitors - 24 microfarads; pulse repetition rate $-100 \mathrm{~Hz}$.

- Sample No. 2 was obtained with the following installation parameters: the voltage on the electrodes is $100 \mathrm{~V}$; capacity of discharge capacitors - 65.5 microfarad; pulse repetition rate $-100 \mathrm{~Hz}$.

- Sample No. 3 was obtained with the following installation parameters: the voltage on the electrodes is $100 \mathrm{~V}$; capacity of discharge capacitors - 24 microfarads; pulse repetition rate $-125 \mathrm{~Hz}$.

- Sample No. 4 was obtained with the following installation parameters: the voltage on the electrodes is $100 \mathrm{~V}$; capacity of discharge capacitors - 65.5 microfarad; pulse repetition rate $-130 \mathrm{~Hz}$.

- Sample No. 5 was obtained with the following installation parameters: the voltage on the electrodes is $100 \mathrm{~V}$; capacity of discharge capacitors - 65.5 microfarad; pulse repetition rate $-155 \mathrm{~Hz}$.

- Sample No. 6 was obtained with the following installation parameters: voltage on the electrodes - $150 \mathrm{~V}$; capacity of discharge capacitors - 65.5 microfarad; pulse repetition rate $-200 \mathrm{~Hz}$.

\section{Experimental results and discations}

The results of X-ray microanalysis of sample No. 1 are shown below in Figure 3 and in Table 1. 


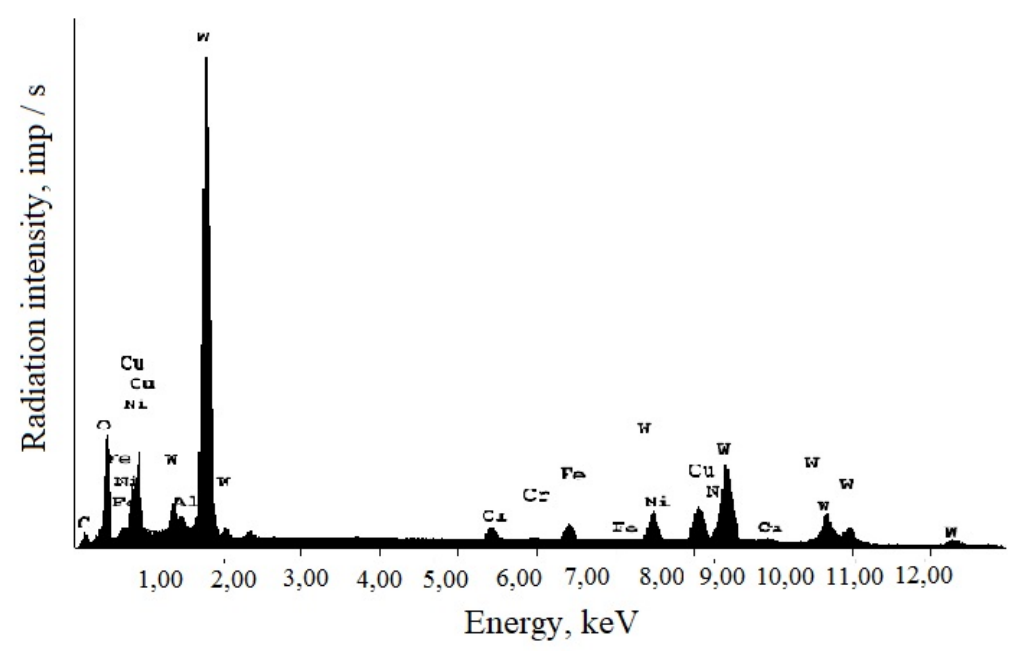

Fig. 3. X-ray microanalysis on the surface

Table 1. Surface element composition

\begin{tabular}{|c|c|c|}
\hline Element & Mass fraction, $\%$ & Atomic share, $\%$ \\
\hline $\mathrm{C}$ & 1,46 & 8,70 \\
\hline $\mathrm{O}$ & 8,67 & 38,81 \\
\hline $\mathrm{Al}$ & 0,68 & 1,80 \\
\hline $\mathrm{Cr}$ & 1,42 & 1,95 \\
\hline $\mathrm{Fe}$ & 2,53 & 3,25 \\
\hline $\mathrm{Ni}$ & 5,99 & 7,30 \\
\hline $\mathrm{Cu}$ & 9,96 & 11,22 \\
\hline $\mathrm{W}$ & 69,29 & 26,98 \\
\hline Total & 100,00 & 100,00 \\
\hline
\end{tabular}

The results of X-ray microanalysis of sample No. 2 are shown below in Figure 4 and Table 2 .

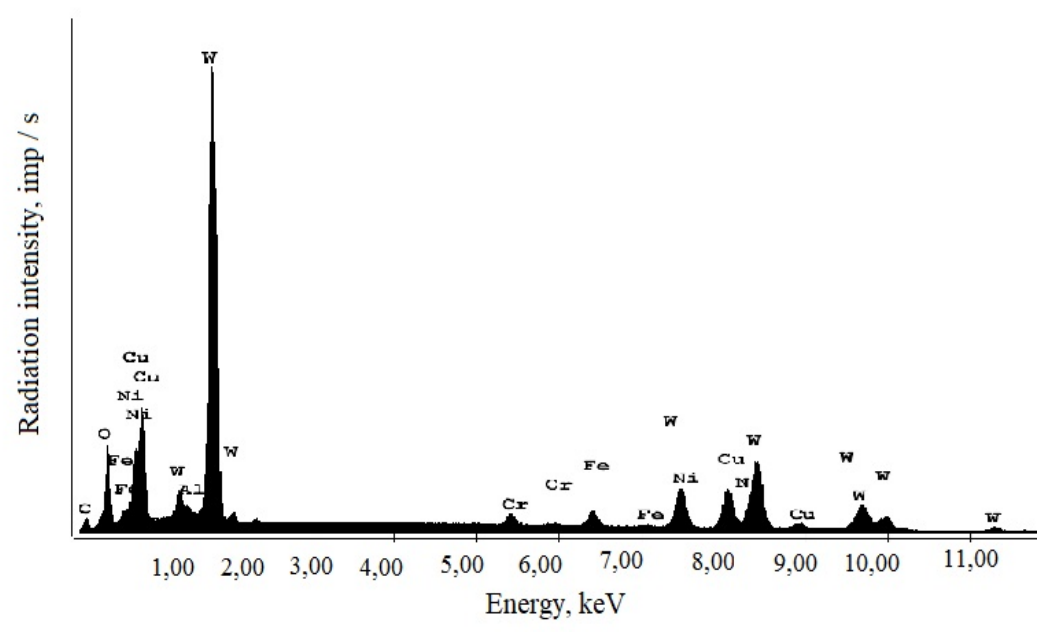

Fig. 4. X-ray microanalysis on the surface 
Table 2. Surface element composition

\begin{tabular}{|c|c|c|}
\hline Element & Mass fraction, $\%$ & Atomic share, $\%$ \\
\hline $\mathrm{C}$ & 1,92 & 11,30 \\
\hline $\mathrm{O}$ & 7,54 & 33,32 \\
\hline $\mathrm{Al}$ & 0,65 & 1,70 \\
\hline $\mathrm{Cr}$ & 1,31 & 1,78 \\
\hline $\mathrm{Fe}$ & 2,33 & 2,95 \\
\hline $\mathrm{Ni}$ & 8,65 & 10,42 \\
\hline $\mathrm{Cu}$ & 11,93 & 13,27 \\
\hline $\mathrm{W}$ & 65,68 & 25,26 \\
\hline Total & 100,00 & 100,00 \\
\hline
\end{tabular}

The results of X-ray microanalysis of sample No. 3 are shown below in Figure 5 and Table 3.

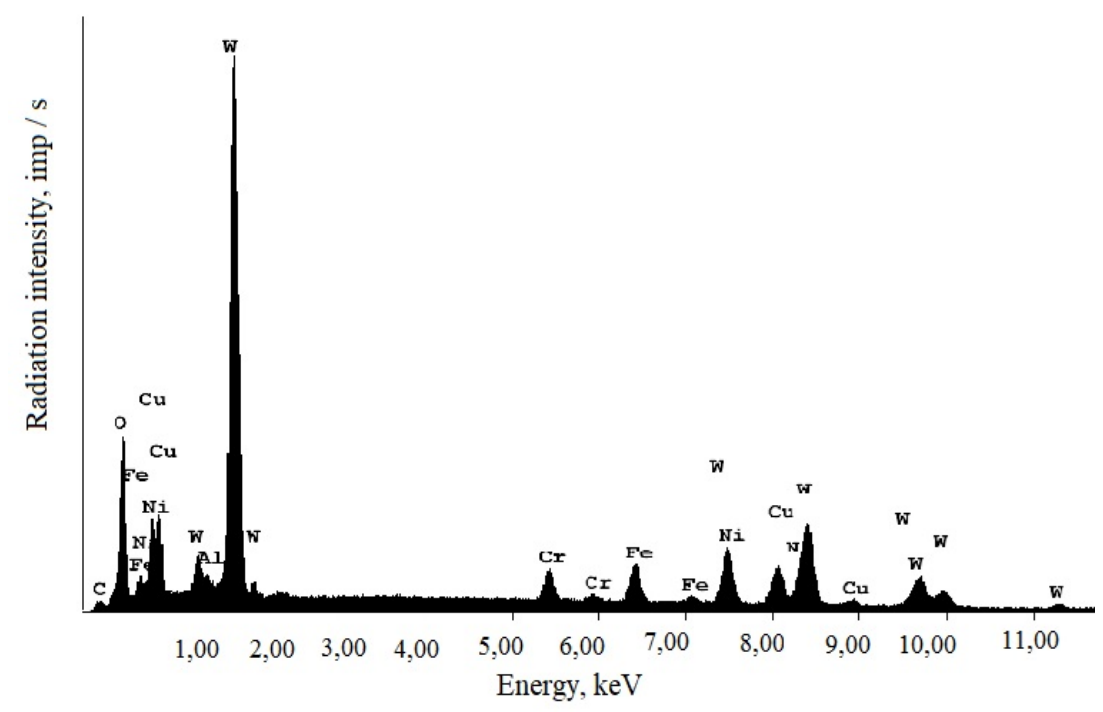

Fig. 5. X-ray microanalysis on the surface

Table 3. Surface element composition

\begin{tabular}{|c|c|c|}
\hline Element & Mass fraction, \% & Atomic share, $\%$ \\
\hline $\mathrm{C}$ & 0,90 & 4,72 \\
\hline $\mathrm{O}$ & 11,47 & 45,30 \\
\hline $\mathrm{Al}$ & 0,44 & 1,04 \\
\hline $\mathrm{Cr}$ & 2,82 & 3,42 \\
\hline $\mathrm{Fe}$ & 4,65 & 5,26 \\
\hline $\mathrm{Ni}$ & 9,62 & 10,36 \\
\hline $\mathrm{Cu}$ & 8,92 & 8,87 \\
\hline $\mathrm{W}$ & 61,18 & 21,03 \\
\hline Total & 100,00 & 100,00 \\
\hline
\end{tabular}

The results of X-ray microanalysis of sample No. 4 are shown below in Figure 6 and Table 4. 


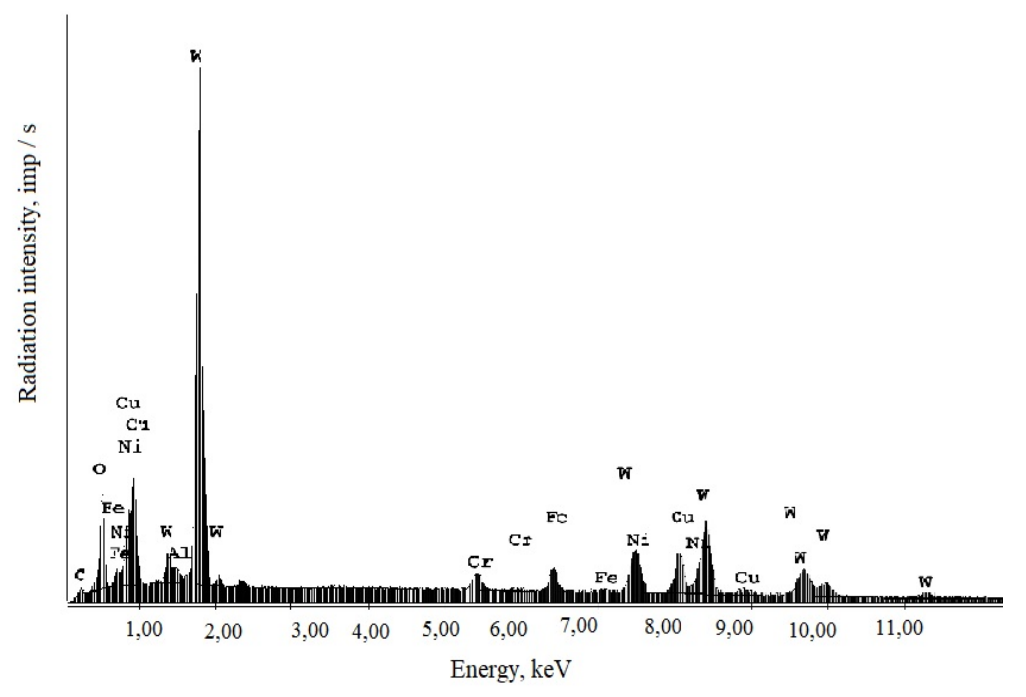

Fig. 6. X-ray microanalysis on the surface

Table 4. Surface element composition

\begin{tabular}{|c|c|c|}
\hline Element & Mass fraction, $\%$ & Atomic share, $\%$ \\
\hline $\mathrm{C}$ & 1,05 & 6,20 \\
\hline $\mathrm{O}$ & 8,27 & 36,68 \\
\hline $\mathrm{Al}$ & 0,72 & 1,90 \\
\hline $\mathrm{Cr}$ & 1,93 & 2,64 \\
\hline $\mathrm{Fe}$ & 3,37 & 4,29 \\
\hline $\mathrm{Ni}$ & 8,77 & 10,59 \\
\hline $\mathrm{Cu}$ & 11,53 & 12,87 \\
\hline $\mathrm{W}$ & 64,35 & 24,83 \\
\hline Total & 100,00 & 100,00 \\
\hline
\end{tabular}

The results of X-ray microanalysis of sample No. 5 are shown below in Figure 7 and in Table 5 .

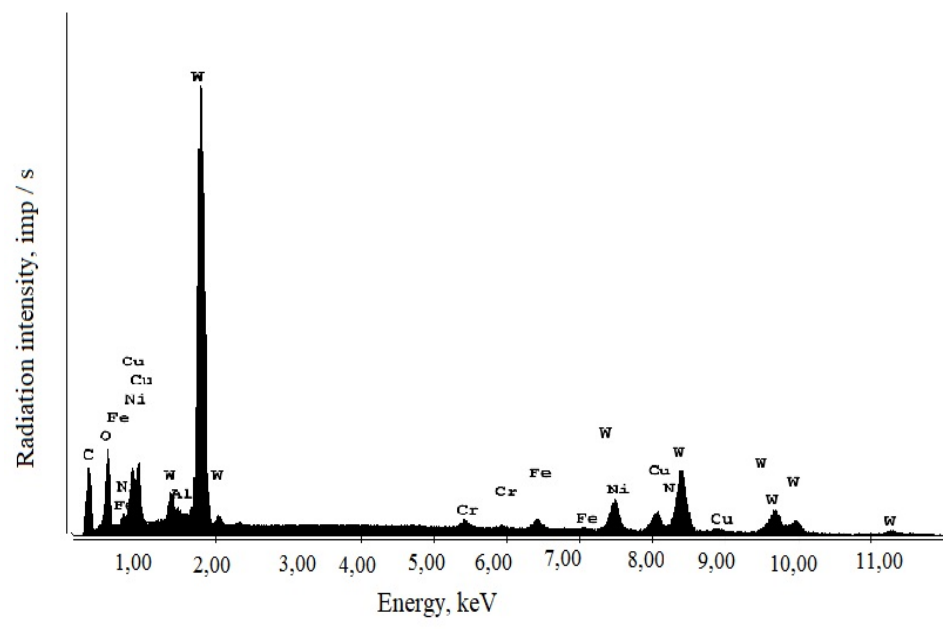

Fig. 7. X-ray microanalysis on the surface 
Table 5. Surface element composition

\begin{tabular}{|c|c|c|}
\hline Element & Mass fraction, $\%$ & Atomic share, $\%$ \\
\hline $\mathrm{C}$ & 10,08 & 42,07 \\
\hline $\mathrm{O}$ & 7,95 & 24,90 \\
\hline $\mathrm{Al}$ & 0,61 & 1,14 \\
\hline $\mathrm{Cr}$ & 1,09 & 1,05 \\
\hline $\mathrm{Fe}$ & 1,85 & 1,66 \\
\hline $\mathrm{Ni}$ & 7,59 & 6,48 \\
\hline $\mathrm{Cu}$ & 6,58 & 5,19 \\
\hline $\mathrm{W}$ & 64,26 & 17,52 \\
\hline Total & 100,00 & 100,00 \\
\hline
\end{tabular}

The results of X-ray microanalysis of sample No. 6 are shown below in Figure 8 and in Table 6.

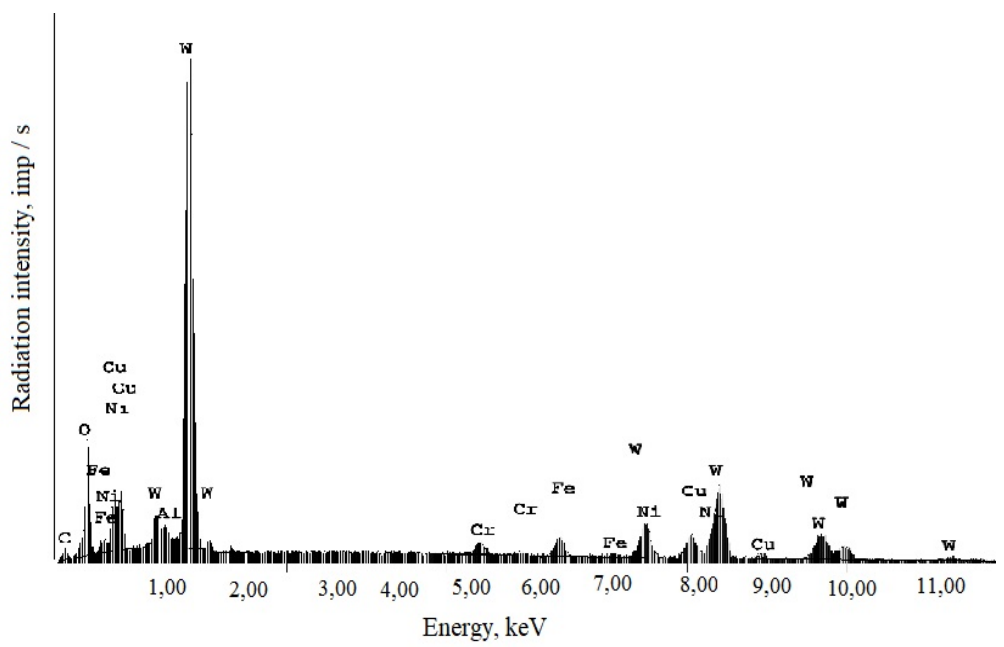

Fig. 8. X-ray microanalysis on the surface

Table 6. Surface element composition

\begin{tabular}{|c|c|c|}
\hline Element & Mass fraction, $\%$ & Atomic share, $\%$ \\
\hline $\mathrm{C}$ & 1,34 & 7,44 \\
\hline $\mathrm{O}$ & 10,45 & 43,63 \\
\hline $\mathrm{Al}$ & 1,03 & 2,54 \\
\hline $\mathrm{Cr}$ & 1,70 & 2,18 \\
\hline $\mathrm{Fe}$ & 2,92 & 3,50 \\
\hline $\mathrm{Ni}$ & 7,74 & 8,81 \\
\hline $\mathrm{Cu}$ & 6,84 & 7,19 \\
\hline $\mathrm{W}$ & 67,99 & 24,71 \\
\hline Total & 100,00 & 100,00 \\
\hline
\end{tabular}

It was established experimentally that the main elements of sample No. 1 are tungsten, copper, oxygen and nickel, carbon, chromium and iron are also present in a small amount, and an element such as aluminum is contained in an amount of less than $1 \%$.

The main elements of sample 2 are tungsten, copper, oxygen and nickel, carbon, chromium and iron are also present in a small amount, and an element such as aluminum is contained in an amount of less than $1 \%$. 
The main elements of sample No. 3 are tungsten, copper, oxygen, iron and nickel, a small amount of chromium is also present, and elements such as aluminum and carbon are contained in less than $1 \%$.

The main elements of sample No. 4 are tungsten, copper, oxygen and nickel, carbon, chromium and iron are also present in a small amount, and an element such as aluminum is contained in an amount of less than $1 \%$.

The main elements of sample No. 5 are tungsten, copper, oxygen, carbon and nickel, a small amount of chromium and iron are also present, and an element such as aluminum is contained in an amount of less than $1 \%$.

The main elements of sample No. 6 are tungsten, copper, oxygen and nickel; carbon, chromium, aluminum and iron are also present in a small amount.

Conducted research aimed at establishing the elemental composition of powders, obtained by electroerosion dispersion of the alloy W-Ni-Fe, will determine the most rational area of their practical application.

\section{References}

1. A.A. Lipatov, Reactive diffusion in cutting high-alloy steel by means of a hard-alloy tool, Russian Engineering Research, 2013, vol. 33, No. 3, pp. 144-149.

2. A.M. Adaskin, A.A. Vereshchaka, A.S. Vereshchaka, Study of wear mechanism of hard-alloy tools during machining of refractory alloys, Journal of Friction and Wear, 2013, vol. 34, No. 3, pp. 208-213.

3. V.L. Bibik, Forecasting of hard-alloyed cutting tool resistance based on thermal diffusivity, Materials Science Forum, 2013, vol. 762, pp. 777-781.

4. E.V. Azarova, E.A. Levashov, V.G. Ralchenko, A.P. Bolshakov, E.E. Ashkinazi, Creation of strong adhesive diamond coatings on hard alloy by electric-spark alloying, Metallurgist, 2010, vol. 54, № 7-8, pp. 523-529.

5. Z. Qiao, X. Ma, W. Zhao, H. Tang, B. Zhao, Nanostructured novel cemented hard alloy obtained by mechanical alloying and hot-pressing sintering and its applications, Journal of Alloys and Compounds. 2008. vol. 462. No. 1-2. pp. 416-420.

6. S.S. Nayak, S.K. Pabi, M. Wollgarten, J. Banhart, B.S. Murty, Nanocomposites and an extremely hard nanocrystalline intermetallic of al-fe alloys prepared by mechanical alloying, Materials Science and Engineering: A, 2010, vol. 527, No. 9, pp. 2370-2378.

7. K. Maruyama, T. Nonaka, H.Y. Kim, Effects of $\alpha 2$ spacing on creep deformation characteristics of hard oriented pst crystals of tial alloy, Intermetallics, 2005, vol. 13, No. 10, pp. 1116-1121.

8. A. Shenhar, I. Gotman, S. Radin, P. Ducheyne, Microstructure and fretting behavior of hard tin-based coatings on surgical titanium alloys, Ceramics International, 2000, T. 26, No. 7, pp. 709-713.

9. E.V. Ageev, R.A. Latypov, Fabrication and investigation of carbide billets from powders prepared by electroerosive dispersion of tungsten-containing wastes, Russian Journal of Non-Ferrous Metals, 2014, vol. 55, No. 6, pp. 577-580.

10. Latypov, R.A. Electroerosion Micro- and Nanopowders for the Production of Hard Alloys / Latypov R.A., Latypova G.R., Ageeva E.V., Kruglyakov O.V. // Russian Metallurgy (Metally), Vol. 2016, No. 6, pp. 547-549. 
11. E.V. Ageev, R.A. Latypov, E.V. Ageeva, Investigation into the properties of electroerosive powders and hard alloy fabricated from them by isostatic pressing and sintering, Russian Journal of Non-Ferrous Metals, 2015, vol. 56, No. 1, pp. 52-62.

12. E.V. Ageeva, I.A. Avilova, N.M. Horyakova, Preparation of Copper Electroerosion Nanopowders from Waste of Aquatic Medium and its Validation by Physicochemical Methods, Applied Mechanics and Materials, 2015, vol. 770, No. 1, pp. 23-27.

13. Ageeva, E. V. Installation for production of powder materials suitable for technological processes of restoration and strengthening of details / Ageeva E. V., Zubarev M. A. / works of GOSNITI. - Moscow: all-Russian research technological Institute of repair and operation of machine-truck, 2017 - №129. - P. 169-173.

14. Ageev, E. V. Analysis of the characteristics of wear resistance of nanocomposite coatings obtained using electroerosion materials / Ageev E. V., Pickalov V. S., Khardikov S. V., Zubarev M. A. // Proceedings of the SWSU. - Kursk: SWSU, 2016 - №6 (69). - P. 40-49.

15 Latypov, R.A. Coatings Fabricated by Plasma-Jet Hard-Facing by Dispersed Mechanical Engineering Wastes / Latypov R.A., Ageev E.V., Latypova G.R., Altukhov A.Yu.,

Ageeva E. V. // Metallurgy (Metally), Vol. 2018, No. 6, pp. 573-575.

16. Latypov, R.A. Manufacture of Cobalt-Chromium Powders by the Electric Discharge Dispersion of Wastes and Their Investigation / Latypov R.A., Ageev E.V., Altukhov A.Yu.,

Ageeva E. V. // Metallurgy (Metally), Vol. 2018, No. 12, pp. 1177-1180.

17. G.R. Latypova, N.N. Karpenko, V.V. Yaroshenko, Elementary composition of powder particles obtained by electro-erosion dispersion of waste of tool steel R18 / In the collection: Advanced technologies and processes Collection of scientific articles of the 5th All-Russian Scientific and Technical Conference with international participation. Executive editor

A.A. Gorokhov. 2018. pp. 174-176.

18. V.Yu. Chaplygin, G.R. Latypova, E.V. Ageev, X-ray diffraction analysis of copper alloy powder obtained by the method of electroerosive dispersion // News of SouthWest State University, Technology and Technology Series, 2016, №3, pp. 47-51.

19. Ageev E.V., Karpenko V.Yu., Latypov R.A. Composition, structure and properties of high-speed steel powder obtained by electroerosion dispersion in water // international technical and economic journal, 2014, No. 5, pp. 88-96. 